\title{
Epilepsy and early-onset overgrowth syndrome revealing Sotos syndrome
}

Epilepsia e síndrome de crescimento excessivo de início precoce revelando a síndrome de Sotos

Wladimir Bocca Vieira de Rezende Pinto', Paulo Victor Sgobbi de Souza', Thiago Bortholin', Erika Lopes

Honorato', Leonardo Favi Bocca ${ }^{1}$, Acary Souza Bulle Oliveira ${ }^{1}$

A 44-year-old woman presented with childhood-onset refractory complex partial seizures. Medical history revealed neonatal macrosomia and hypotonia, early-onset overgrowth in infancy, macrocephaly and mild intellectual disability. Examination revealed macrodolichocephaly with prominent forehead and facial dysmorphisms, scoliosis, largehands and arachnodactyly(Figure 1). Neuroimaging showed macrocerebellum, ventriculomegaly and persistent cavum septum pellucidum (Figure 2). Clinical and neuroimaging features were diagnostic of Sotos syndrome.

Sotos syndrome or cerebral gigantism is an autosomal dominant or sporadic disorder characterized by early-onset overgrowth syndrome, typical facial dysmorphisms, global developmental delay, epilepsy ${ }^{1}$ and neuroimaging findings including midline defects, enlargement of ventricles and macrocerebellum².
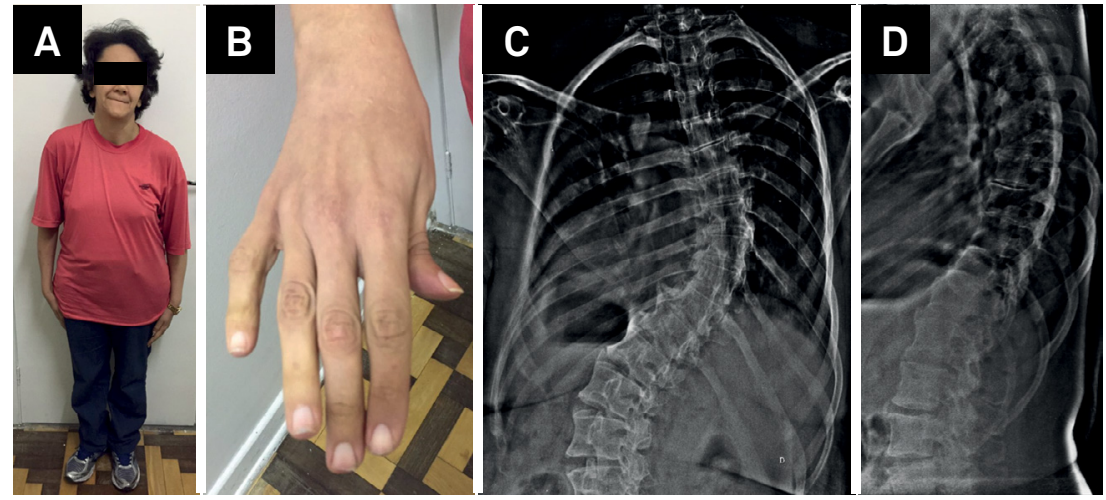

Figure 1. Dysmorphisms in Sotos syndrome. (A-B) Examination disclosing large prominent forehead, pointed chin, large hand with arachnodactyly and marked scoliosis (C) and lumbar hyperlordosis (D) in X-ray studies.
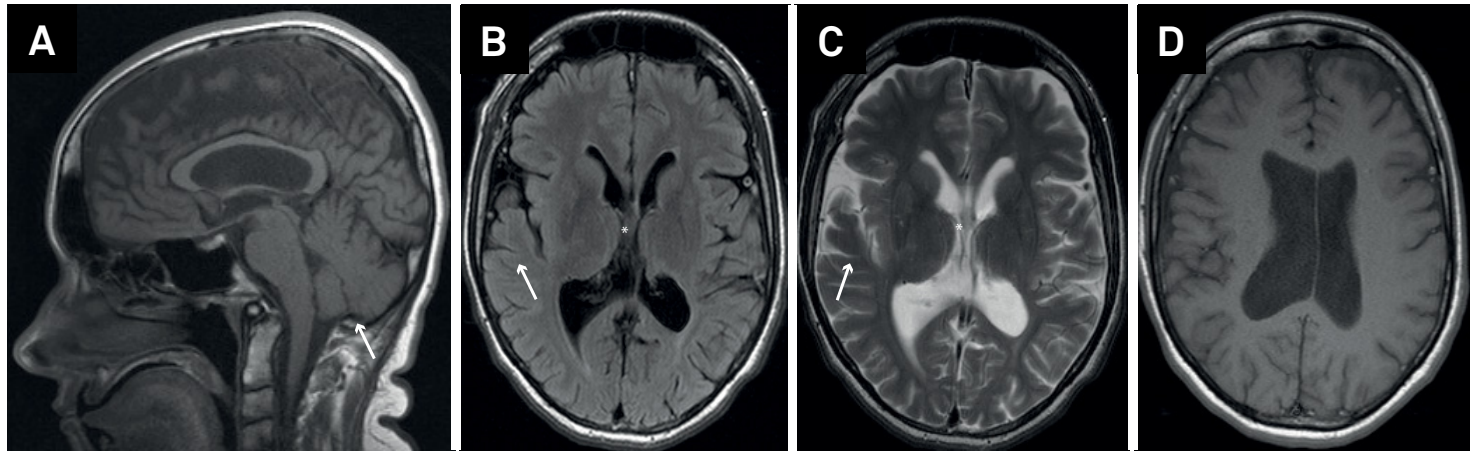

Figure 2. Neuroimaging findings in Sotos syndrome. (A) Sagittal brain MR imaging disclosing macrocerebellum (white arrow) in T1-weighted images. Axial brain MR imaging showing right hippocampal and temporal lobe malrotation with atrophy (white arrow-head), persistent cavum septum pellucidum (asterisk), ventriculomegaly with prominence of the occipital horns and mild brain asymmetry.

References

1. Tatton-Brown K, Rahman N. Sotos syndrome.

Eur J Hum Genet. 2007;15(3):264-71.

http://doi.org/10.1038/sj.ejhg.5201686
2. Horikoshi H, Kato Z, Masuno M, Asano T, Nagase T, Yamagishi Y et al. Neuroradiologic findings in Sotos syndrome.J Child Neurol. 2006;21(7):614-8. http://doi.org/10.1177/08830738060210071001

${ }^{1}$ Universidade Federal de São Paulo, Departamento de Neurologia e Neurocirurgia, Divisão de Doenças Neuromusculares, São Paulo SP, Brasil.

Correspondence: Wladimir Bocca Vieira de Rezende Pinto; Departamento de Neurologia e Neurocirurgia da UNIFESP; Rua Estado de Israel, 899 ; $04022-002$

São Paulo SP, Brasil; E-mail: wladimirbvrpinto@gmail.com

Conflict of interest: There is no conflict of interest to declare.

Received 23 July 2016; Accepted 03 October 2016. 